\title{
The Road to Doctoral Success and Beyond
}

\author{
Veronica Castro \\ Educational Psychology \\ Department, University of \\ Texas-Pan American, \\ Edinburg, TX, USA
}

castrov@utpa.edu

Javier Cavazos Jr.

Counseling and Educational

Psychology Department, Texas

A\&M University-Corpus Christi, Corpus Christi, TX, USA

javier.cavazos@tamucc.edu

\author{
Elda E. Garcia \\ Assessment and \\ Accountability, Corpus Christi \\ Independent School District, \\ Corpus Christi, TX, USA
}

eegarcia@ccisd.us

\author{
Alma Y. Castro \\ Sociology Department, \\ University of Massachusetts- \\ Amherst, Amherst, MA, USA
}

aycastro@soc.umass.edu

\begin{abstract}
The purpose of this study is to gain an understanding of the experiences of women that lead them to pursue a Ph.D in Counseling, as well a study of their experiences in their doctoral program. The goal of this study is to identify those factors related to women's academic success. This study applies the resiliency and emotional intelligence (EI) framework to analyze the subjects' experiences. Another construct related to EI and resilience, Antonovsky's (1987) theory of coherence, is employed to explain the way in which the subjects converted negative external factors into achievement motivation. A three and a half hour focus group, facilitated by an open-ended questionnaire, was audio-recorded, transcribed, and analyzed independently by the four researchers. The results found two overarching themes, consistent with previous research by Amini et al. (2008): (a) attributes, attitudes, and motivation and (b) extrinsic supportive factors. Another theme uncovered in this study was the impact of (c) negative external factors. The paper concludes with a discussion of these findings, suggestions for future research, and ideas for ways in which doctoral programs and faculty can promote the success of female doctoral students.
\end{abstract}

Keywords: resiliency, academic achievement, women, doctoral students, sense of coherence

Material published as part of this publication, either on-line or in print, is copyrighted by the Informing Science Institute. Permission to make digital or paper copy of part or all of these works for personal or classroom use is granted without fee provided that the copies are not made or distributed for profit or commercial advantage AND that copies 1) bear this notice in full and 2) give the full citation on the first page. It is permissible to abstract these works so long as credit is given. To copy in all other cases or to republish or to post on a server or to redistribute to lists requires specific permission and payment of a fee. Contact Publisher@InformingScience.org to request redistribution permission.

\section{Introduction}

Recent statistics illustrate that more women than men are enrolled in higher education institutions (U.S. Department of Education, 2009). Historically, more men had always been enrolled in universities. Beginning in 1980, women began to outnumber men in universities (U.S. Department of Education, 2009). What 
does this upsurge of women in education indicate? What helps women become academically resilient? Do resilient women need a supportive environment, community support, and/or school support in order to achieve academic success?

Despite the academic progress of women in the U.S., fewer women complete professional and doctoral degrees, as compared to men (U.S. Bureau of the Census, 2009a, 2009b). While women have higher graduation rates than men at most levels of education, the trend ends at the master's degree. After the master's degree, there is a one and half percent difference between genders in completion of doctoral degrees, with men in the lead (U.S. Bureau of the Census, 2009a, 2009b). Approximately 672,000 fewer women than men complete a doctoral degree (U.S. Bureau of the Census, 2009a, 2009b). Further investigations into the demographics of the women who complete doctoral degrees indicate that minority women represent a very small percentage. For example, Latina women represent only $4 \%$ of total women obtaining a doctoral degree (U.S. Bureau of the Census, 2009a, 2009c). Thus, women, especially minority women, have greater obstacles to doctoral educational attainment (Gardner, 2008).

An exploration of women's history in education reveals that women have had to fight for their right to attain doctoral degrees in all fields (Weiler, 1989). Other studies have highlighted women's caretaker responsibilities, financial constraints, and lack of guidance as obstacles to obtaining advanced degrees (Eitel \& Martin, 2009; Heenan, 2002). "In regard to socialization, academic structures, conventions, and traditions are typically not designed to allow [graduate/doctoral] students with children, whose schedules and responsibilities are often demanding, much flexibility" (Gardner, 2008, pp. 133-134). Thus, challenges for women to complete their doctoral requirements abound. As Curtis (2005) noted, "legal, formal, and visible hurdles have been largely, though not entirely, removed, leaving in their stead more subtle structural disadvantages: forms of bias and discrimination that could almost be characterized as unconscious or unintended" (p. 1). While women have had greater access to education, there still seem to be obstacles that hinder their educational success.

So, what experiences and/or characteristics help women succeed or persevere in higher education? The researchers conducted a focus group of women enrolled in a doctoral counseling program in order to determine the factors, experiences, and/or characteristics pertinent to their entryand exit-level doctoral success. One way to understand what has led to these women's success is to utilize the resiliency theoretical framework. Therefore, the resiliency construct was utilized to analyze the data. While there has been extensive research on resiliency, few studies have focused on the factors, life events, or personal characteristics that have led women to become successful in doctoral programs (Gardner, 2008).

Why is this type of research important? Statistics indicate that women, especially ethnic minorities, are less likely to obtain a professional/doctoral degree despite higher enrollment (U.S. Bureau of the Census, 2009a, 2009c; U.S. Department of Education, 2009). This indicates that women are at greater risk for graduate school/doctoral program attrition. In fact, a study on Ph.D. attrition rates by the Council of Graduate Schools (CGS) (2008) found that the attrition rate for women enrolled in Ph.D. programs is higher than men. So, in spite of the advancement of women in education, they are less likely to reach the ivory tower.

Professionals in higher education, like most professionals, are held to ethical standards. According to the ethical principles and standards of American College Personnel Association (ACPA) College Student Educators International (American College Personnel Association, 2006), educators in higher education should "enhance the worth, dignity, potential, and uniqueness of each individual within post-secondary educational institutions" (n.p.). This statement speaks to the ethical principle of responsibility to society. Advocacy, especially for minority populations like His- 
panic women, is one way educators can be ethically responsible. For this reason, attrition of female doctoral students should be an important issue for doctoral program faculty.

While some research has focused on the characteristics of individuals who are academically successful, few have focused on the unique experience of the women who reach the highest level of academic achievement (Gardner, 2008). Therefore, the purpose of this study was to identify characteristics and general themes of resiliency among female doctoral students. Thus, the guiding research questions in this study were, 'How do women in a Ph.D. counseling program understand and perceive their reason for academic success?' and 'Are there unique resiliency characteristics in women who pursue a doctoral degree?'

Specifically, the researchers were interested in the women's (a) school experience, (b) perceptions of the impact of mentors on their academic achievement, (c) perceived barriers to educational attainment, and (d) significant life events that contributed to their academic success. The purpose of this study was to provide insight into these questions and reveal factors that allowed these women to succeed in their pursuit of higher education. This type of research may allude to characteristics needed for women to succeed in doctoral programs. Results of this research can also have implications for how graduate programs are structured in order to ensure optimal matriculation rates.

This article provides a literature review that focuses on resiliency and related constructs. Second, findings from personal interviews with seven female doctoral students are introduced. Lastly, a discussion regarding the importance of these findings is provided and implications for practice and research are offered.

\section{Literature Review}

The interest in factors that provide strength in individuals can be traced back to Indian Buddhism, Chinese medicine, and ancient Greece and Rome (Strumpfer, 2005). Strumpfer (2005), borrowing from Antonovsky's (1979) term fortology, calls this line of study, psychofortology. This term translates to the origins of strength. While many different fields have contributed to the study of strength in individuals, the field of resiliency is one of the most prominent. Nevertheless, other fields studying psychofortology will be reviewed, as they add depth to the discussion of the current study.

\section{Resiliency}

Resiliency is defined as "the ability to cope with adversity and overcome the most challenging circumstances" (Hassinger \& Plourde, 2005, p. 319). Academic resilience is the ability to achieve in an educational setting despite exposure to risk factors (Morales, 2008). McMillan and Reed (1994) contend that positive interpersonal and individual factors play a role in developing academic resiliency. Examples of positive interpersonal relationships include high expectations from family and/or mentor support. Familial support in academic success is best exemplified in parents who hold high educational expectations and provide their children with the encouragement to pursue those expectations (McMillan \& Reed, 1994). For example, Zalaquett (2006) found the following factors vital in the academic success of Latino college students: familial support, high value of education, and responsibility toward siblings. Participants in Zalaquett's (2006) study emphasized the importance of family support via words of encouragement.

Another important and influential extrinsic factor, which may compensate for lack of family support, is the school environment. Conditions in the school environment appear to play a role in helping students develop resiliency and their eventual academic achievement. For example, Latina/o high school students who have positive role models or mentors, such as teachers, coaches, and counselors, can become resilient (Cavazos \& Cavazos, 2010; Zalaquett \& Feliciano, 2004). 
Additionally, Rak and Patterson (1996) affirm that educators can help students by incorporating the principle of salutogenesis, by working from the individual's strengths, by demonstrating unconditional positive regard, by teaching resiliency and conflict-resolution skills, by modeling for students, and by focusing on building students' self-concept.

Further support for the positive influence of school environment is also offered in graduate level studies. For example, Hoskins and Goldberg (2005) investigated persistence among 33 current and former students ( 28 were Caucasian) from doctoral programs. As noted by Hoskins and Goldberg, two components comprised program-match: academic and social-personal. Academic match referred to a positive relationship between students' goals and aspirations with doctoral program and coursework, whereas social-personal match involved relationships with faculty and peers (Hoskins \& Goldberg, 2005). Additionally, Protivnak and Foss (2009) looked at factors that influenced the experiences of predominantly 141 Caucasian counselor education students. Using an online questionnaire to collect qualitative data, the researchers found that students had positive and negative experiences with (a) departmental culture, (b) mentoring, (c) academics, (d) support systems, and (e) personal issues. Although some doctoral students perceived supportive faculty and a positive department culture, other students described faculty as unsupportive and too busy to provide guidance to beginning doctoral students, as well as a department that was filled with politics.

In addition to Anglos and Latinas/os, recent attention has focused on African American doctoral students in education. L. D. Patton and Harper (2003) described the importance of same-sex mentoring among African American women in post-bachelor programs. Participants in this study reflected on the benefits of having an African American female mentor at a predominantly White university. Such benefits included (a) learning survival skills, (b) having a mother figure in academia, and (c) feeling a sense of comfort. Additionally, Lewis, Ginsberg, Davies, and Smith (2004) investigated the lived experiences and barriers to completion among eight doctoral students at a predominantly White university. Using qualitative methods to examine the aforementioned questions, these researchers found that African American doctoral students experienced the following: feelings of isolation, feeling different, a positive relationship with peers, and successfully negotiating the university system. It is important to note that some participants in this study reported that they thought about leaving their doctoral program as a result of perceptions of isolation. Based on subsequent research (Torres \& Driscoll, 2010), African Americans confirm their perceived positive and negative experiences in their doctoral programs.

Most resiliency research shows that academically successful students have access to resources such as family, school, and/or community (Casanova, Garcia-Linares, de la Torre, \& de la Villa Carpio, 2005; Evans-Winters, 2003; Gonzalez, 2002; McNair \& Johnson, 2009; Ruiz, 2002; Trevino, 2000). Research on student resiliency also highlights the importance of mentoring (Hassinger \& Plourde, 2005; Montano, 1998; Zalaquett \& Feliciano, 2004). Often, it is people in the lives of youth who facilitate their eventual academic achievement. Thomsen (2002) reported, "The research on resilient people often reveals that a school experience or staff person had made the most significant difference in a young person's life" (p. x). For instance, Ceballo (2004) interviewed 10 Latina/o college students and found parents' emphasis on pursuing higher education, the establishment of autonomy, nonverbal support from parents for higher education, and the importance of mentors and role-models were important in their eventual academic achievement. Numerous participants mentioned that they may not have pursued higher education without the support and guidance from mentors such as school counselors and teachers (Ceballo, 2004). Similar findings support the important role mentors play in the successful completion of terminal degrees by women, especially minority women (Portillo, 2007).

Second, resilient students have high levels of intrinsic motivation, which includes participating in an activity for self-interest, challenge, or enjoyment (Brehm, Kassin, \& Fein, 2005). Bernard 
(1997) and Thomsen (2002) contend that resilience is comprised of internal characteristics such as one's temperament, ability to elicit positive responses from others, empathy, communication skills, sense of humor, individual identity, being independent, ability to disassociate one's self from unhealthy situations or people, and having a sense of purpose or future. Bernard (1997) and Thomsen (2002) also contend that these internal characteristics can be fostered in individuals. In a study of successful Latina/o college students, Zalaquett and Feliciano (2004) highlighted the importance of resilience and determination. A student provided the following account of his resilient efforts, "Although I had to go through many hardships and obstacles to get to where I am today, I managed to pull through because I refused to give up" (p. 16).

Research indicates that resilience can increase when life/social skills are taught (Bosworth \& Earthman, 2002; Werner \& Smith, 1992). "Children are inherently vulnerable, but also they are strong in a determination to survive and grow" (Radke-Yarrow, Sherman, Mayfield, \& Stilwell, 1990, p. 97). Additionally, Nelson and Low (2003) and Wolin and Wolin (1993) assert that resilient behaviors can be learned and then practiced until they become internal strengths. In other words, students who are resilient exhibit certain characteristics or qualities that enable them to overcome difficult or devastating circumstances, and students who are not resilient can be taught skills that will enhance their resiliency. Hence, teachers can directly affect extrinsic factors and indirectly develop intrinsic factors in students.

Third, resilient students set clear and high goals regarding their future. McMillan and Reed (1994) use the term reality checks to describe an event in a student's life, such as growing up in poverty, which illustrates the importance of setting high educational goals and demonstrates that opportunities are minimal without higher education. Fourth, resilient students have an internal locus of control and believe that (a) effort and hard work are important and (b) goals are influenced by these individual actions (Rotter, 1954). Lastly, resilient students have positive selfefficacy, which is the belief in one's aptitudes (Bandura, 1995).

A study conducted by Amini et al. (2008) revealed four themes that medical students believed led to their doctoral success: (1) personal abilities; (2) attitude, beliefs, and motivation; (3) effort and perseverance; and (4) supportive factors. Medical students in Amini et al.'s study believed that intelligence, creativity, and focus were vital to their academic success. These medical students also highlighted the importance of endurance in their success. In fact, "effort was mentioned more important than intelligence in medical schools" (Amini et al., 2008, p. 349). This statement revealed the medical students' belief in perseverance. Lastly, mentor support from medical school professors and family support were also deemed important.

In summary, research on resilience indicates that resilient students have good social skills, positive self-esteem, a positive sense of the future, support from mentors or peers, and a high level of overall achievement in school (Grayson, 2001). McMillan and Reed (1994) validate that the development of resiliency involves a combination of intrinsic and extrinsic factors.

\section{Salutogenesis}

The theory of resiliency and the theory of salutogenesis, created by Antonovsky (1979), have many overlapping constructs (Almedom, 2005). Salutogenesis, associated with sociology and medical fields, focuses on the origins of strength and health (Antonovsky, 1979). The purpose of salutogenesis was to explain how individuals remain well or even thrive despite being exposed to stressors (Antonovsky, 1979).

Salutogenesis is operationalized by the construct sense of coherence (SOC) (Antonovsky, 1987). Sense of coherence is comprised of three facets: comprehensibility, manageability, and meaningfulness (Antonovsky, 1987). "A Sense of Coherence (SOC) relates to the way in which human agents make sense of the world, use the required resources to respond to it and feel that these re- 
sponses are meaningful and make sense emotionally" (Harrop, Addis, Elliot, \& Williams, 2006, p. 7). Comprehensibility in this case refers to an individual's ability to make sense of his or her adversity (Almedom, 2004). Additionally, manageability refers to individuals' sense that they can handle whatever comes their way, whereas meaningfulness refers to individuals' ability to attach meaning and worth to the endeavors they pursue. In other words, challenges are seen as something to overcome. Antonovsky $(1979,1987)$ contends that a strong sense of coherence translates into individuals that can successfully cope with stressors. Thus, a person with a strong sense of coherence can be described as resilient.

Existing research on salutogenesis has been quantitative in nature and focused on the constructs related to SOC (Harrop et al., 2006). Additionally, the use of SOC research has been limited to medical sociology, occupational health, and mental health fields. Even then, research on SOC fails to "measure how sense of coherence is shaped by historical and structural process of which individuals are a part" (Harrop et al., 2006, p. 9). A solution to this problem is to conduct qualitative research that captures the nuances of SOC, in order to reveal how SOC works in different contexts (Harrop et al., 2006).

\section{Emotional Intelligence}

Emotional intelligence is another construct relevant to resilience and pertinent to this literature review. Nelson, Low, Stottlemyer, and Martinez (2003) operationally define emotional intelligence as:

... a confluence of learned skills and abilities to (1) accurately know, value, and accept self, (2) establish healthy supportive relationships, (3) get along and work well with others, and (4) deal effectively with the demands and pressures of daily life and work. (p. 7)

Salovey and Mayer (1990) identify five domains of emotional intelligence as self-awareness, managing emotions, motivating self, empathy, and handling relationships. Also, Sternberg (1996) declared that emotionally intelligent people accept that obstacles are part of the challenge, have a can-do attitude, and actively seek out positive role models. These characteristics are highly congruent with resilience and, thus, it appears that resilience and emotional intelligence are constructs that compliment each other. Resiliency is what happens when emotional intelligence is employed.

While research has revealed that personal and social factors are key resiliency traits important to the academic success of college students (Cavazos, Johnson, Fielding, Cavazos, Castro \& Vela, 2010; Zalaquett, 2006), less attention has been given to factors vital in the academic success of female doctoral students (Gardner, 2008). The current study focused specifically on those extrinsic and intrinsic factors that facilitated high academic achievement among seven Latina and White female doctoral students. Although research has uncovered factors that help Latina/o students do well academically, only $8 \%$ of the Latina/o population will attain a post-bachelors degree (Castellanos \& Gloria, 2007). There appears to be potential benefits in better understanding how those who succeed in higher education perceive their life experiences (Morales, 2008), thereby providing insight into what helps women move toward greater academic achievement.

\section{Conclusion}

The review of the literature reveals that there is much overlap among the resilience, SOC, and emotional intelligence constructs. Emotional intelligence, "a confluence of learned skills and abilities" (Nelson et al., 2003, p. 7) is vital to resiliency, "the ability to cope with adversity" (Hassinger \& Plourde, 2005, p. 319). As well, the SOC subscales of comprehensibility, manageability, and meaningfulness contribute to academic resiliency. Therefore, the probability of academic success is high when all three constructs are present in individuals. A basic understanding of re- 
siliency, SOC, and emotional intelligence helps identify intrinsic and extrinsic factors present in the participants in this study. Lastly, the review of literature reveals that additional studies are needed to understand the nuances of resiliency among female doctoral students (Gardner, 2008).

\section{Research Design}

\section{Phenomenological Qualitative Inquiry}

Based on the purpose of the study (How do women in a Ph.D. counseling program understand and perceive their reason for academic success?), it was determined that a phenomenological approach would best help us understand the experiences that led to academic achievement and continued academic success at the doctoral level. One of the basic principles of phenomenology is intentionality. In other words, "humans live (exist) in relation to a world, other persons, and objects; that is, as humans we exist and are constructed by our relations with others" (Olivares, Peterson, \& Hess, 2006, p. 78). Thus, an understanding of individuals' experiences is necessary and vital to the phenomenological approach.

The foundational question for phenomenology is, "What is the meaning, structure, and essence of the lived experience of this phenomenon for this person or group of people?" (M. Q. Patton, 2002 , p. 104). Applied to the research project at hand, namely academic achievement in women, the following questions can be formulated: "How do the relationships and/or experiences with others lead to academic success?" "What experiences do they believe attributed to their academic success and led them to pursue a doctoral degree?" and "What do they believe has been important to their doctoral success?"

In conjunction with the decidedly phenomenological approach, the method chosen for this research was an in-depth, semi-structured group interview or focus group. In a preliminary stage wherein the goal of the research is investigatory in nature, a qualitative methodology is best apt to capture the complexity inherent in the relatively new theoretical framework that is being employed, mainly resiliency theory. Thus, an in-depth, semi-structured focus group was the best fit for the purposes of this research, which is exploration of an underlying context and lived experiences among a group of female doctoral students and not the quantification of such experiences.

\section{Semi-Structured Interview Method}

Barribal and While (1994) contend that semi-structured interviews are "well suited for the exploration of the perceptions and opinions of respondents regarding complex and sometimes sensitive issues and enable probing for more information and clarification of answers" (p. 330). The freedom to probe, a fundamental characteristic of semi-structured interviews, increases the reliability of the data collected by allowing clarification, deeper exploration, and participant recollection (M. Q. Patton, 2002). Based on previous research (Barribal \& While, 1994; Hutchinson \& Skodal-Wilson, 1992; Nay-Brock, 1984; M. Q. Patton, 2002; Smith, 1992), it was determined that a semi-structured interview would be the best methodology for this study.

Dobbert describes 'good' participants as those who comfortably and actively interact with the researcher. "They are generally open and truthful ... they provide solid answers with good detail, they stay on the topic or related important issues, they are thoughtful and willing to reflect on what they say" (as cited in Barriball \& While, 1994, p. 331). M. Q. Patton (2002) describes a good interview as one which "lays open thoughts, feelings, knowledge, and experience, not only to the interviewer but also to the interviewee" (p. 405).

The participants in this study can be described as 'good' participants, according to Dobbert's definition, and the result can be described as a good interview. A real sense of cohesiveness among 
the group was evidenced at the end of the interview, with all of the women laughing and supporting each other. One participant summed it up best by stating,

When I'm here with this group ... I find family that I don't have and I really believe that friends are the family we get to pick. I'm really glad to have all of you and I thank you very much for who you are, what you share, and what we can do together. You know we draw strength from each other.

Barriball and While (1994) also discuss the positive impact an interviewer can have on the validity and reliability of the data. That is to say, if the interviewer's manner or approach is perceived to be friendly and genuine, participants are more inclined to be 'good' participants and thus, participate fully. The fact that two of the researchers belonged to the same cohort is believed to have helped participants fully cooperate in the study. Additionally, the lead researcher's counseling background is also believed to have facilitated the necessary atmosphere conducive to honest participant disclosure.

Focus groups have emerged as a collaborative and empowering approach for feminist research (Wilkinson, 1998); to this end, this approach seemed appropriate for the study of academic resiliency in women. More importantly, a focus group allows for the identification of major themes, which can otherwise be difficult to reveal (Montell, 1999). In sum, research supports interviews and focus groups as an effective way to obtain different attitudes, values, beliefs, and experiences from participants on a given topic (Amini et al., 2008; Barriball \& While, 1994) and that the use of existential phenomenology qualitative inquiry would best answer the research questions for this study.

\section{Interview Design}

The interview design had to be flexible to allow for further probing when needed and structured enough to discuss important experiences relevant to the study. Therefore, the researchers created some open-ended questions to help guide the discussion.

The participants were initially asked four general open-ended questions:

- Describe your elementary, high school, and undergraduate experience.

- Tell us about your doctoral school experience.

- Discuss the experience with mentors you had throughout your academic career.

- Describe any barriers you may have experienced in your pursuit of higher education.

A follow-up question based on the discussion was asked, "Do you believe your disadvantages were barriers to your educational attainment?" The semi-structured interview allowed for the discussion to take a life of its own and tapped into many topics discussed in this study.

The interview process could be described as interactive, where the participants were seen as the experts. It was believed that participants had a unique understanding of the constructs and meaning that helped them achieve academic success. The interviewer facilitated the interview by probing, but was careful not to influence or force the emergence of themes. Rather, the interviewer was attuned to allowing themes to emerge.

The group interview was open and not limited to time. This flexibility in structure allowed participants to go back and forth between predetermined topics as well as new topics unrelated to the open-ended questions.

Prior to the interview, a literature review was conducted to identify previously identified themes in similar studies. The literature review was helpful in highlighting areas which should be dis- 
cussed in the interview. The literature review also helped identify key resiliency themes, which were then narrowed to create focus group questions. Researchers collaborated and revised several drafts of the questions prior to the interview.

\section{Audiotapes and transcripts}

The focus group discussion was audio-taped and responses were transcribed with participants' consent. One researcher took copious notes, while the lead researcher focused on the facilitation of the group. The use of taping ensured accuracy in the recording of data. All participant responses were then transcribed and typed in a single document. Three reviewers identified common themes of resiliency, independently of the other. Additionally, the focus group lasted 3 hours and 42 minutes. It is important to note that the focus group process appeared to be a therapeutic experience for the participants and appeared to result in increased cohesiveness among group members.

\section{Interviewer/researchers}

As previously mentioned, the group facilitator had a counseling certification and had experience as an interviewer. This background helped facilitate the group discussion. The interviewer used counseling techniques, such as paraphrasing, reflection of feeling, and reflection of meaning, that communicated empathy, positive regard, and genuineness.

There are challenges to objectivity when the researcher is a member of the group he/she is investigating (M. Q. Patton, 2002). For example, because the researcher may be so familiar with the group's social experience, he/she may dismiss or overlook relevant themes. Another caveat is that researchers who belong to the social group they investigate may be too invested and, hence, unable to remain objective to themes presented in the interview. However, a strength of an insider perspective, especially with qualitative research, is the ability to fast track the building of trust and rapport with the participants. Additionally, participants' responses did not indicate the inclusion of the interviewer as part of their social group. That is to say, responses did not include statements such as, 'you know what I mean' or 'you know what it's like.'

Two of the four authors were involved with this study from the beginning. Collaboratively, they conducted the literature review, decided on the design, and created the interview questions. The third and fourth authors joined after the results were collected and contributed to the discussion and interpretation of the data. This means that the transcript was analyzed independently by four different individuals. A series of themes were discussed and collectively identified. Participant passages were then organized according to the theme they represented.

\section{Data Collection}

\section{Sample}

Due to the nature of the topic and the theoretical framework employed, the sample is necessarily purposive, meaning that the researchers have "intentionally" chosen the sample "for the specific perspectives they have" (Esterberg, 2002, p. 93). Because the research questions focused on the experiences and/or characteristics unique to female doctoral students, a Ph.D. Counseling doctoral cohort was selected for this study. This particular group was selected because of the area of study -- counseling. It was hypothesized that women in a doctoral counseling program may have a deeper level of introspection about the experiences, characteristics, and/or constructs needed to succeed, than women from other doctoral programs.

Seven of the nine female students from a doctoral cohort participated. Four White women and three Latina women comprised the focus group. The non-participating female doctoral students 
were the researchers in this study. Participants' ages ranged from 28-52. All participants held professional employment in the counseling, education, or administration fields and were in their second year of doctoral studies. In fact, six of the seven participants were certified counselors. Of the seven female students, only two were single, and the rest were married. The two single females did not have any children. Of the five married females, four had children all above the age of 15, with the majority of children already in college. Therefore, most of the children of these doctoral women could be described as self-sufficient.

In order to protect the identity of this study's participants, each participant was provided a pseudonym which is used to identify them throughout this article. Additionally, in order to highlight similarities and/or differences in themes among the ethnicities in these women, we have identified each woman's ethnicity when citing quotes: (W) for White and (L) for Latina.

At the time of the study, the women in this cohort had completed 4 semesters (1.5 years) of doctoral studies and were enrolled in their $5^{\text {th }}$ semester of doctoral studies. For the purposes of this study, doctoral academic success was defined as full-time enrollment, on track with their cohort, and a minimum 3.5 grade point average (GPA). After the study was completed, follow up on this doctoral cohort revealed that all of the women completed all of the requirements needed for their Ph.D., within one and half years after they completed their coursework. Furthermore, six of the seven participants acquired tenure-track professorships at universities across the country. They all remain active in counseling professional organizations and six of the participants continue to progress towards tenure.

\section{Procedure}

Institutional Review Board approval was obtained and informed consent was provided to each participant in written and verbal forms. The informed consent described that participation would pose minimal risk factors. The lead researcher, who was a certified counselor, led the group and reassured participants that she would be available for further processing/counseling, if needed. Additionally, the researchers provided participants with free available counseling resources should they feel the need to consult with someone after participation in this study.

A room in the educational institution, where the participants attended, was reserved for the group interview. Participants were notified of the date, time, and place of the group interview, should they decide to participate. Participants were given the written informed consent one week prior to the group interview. The researchers ensured the privacy of the group by placing "Do not disturb" signs to all entrances to the room. However, a phone available in the room was not disconnected and rang once towards the end of the interview.

After all of the participants were present, the researchers provided another hard copy of the informed consent and verbally reviewed the information. The researchers briefly highlighted the purpose of the study and then began with the open-ended questions.

\section{Observations}

During the group interview, one of the researchers made observations and noted them. Her observations indicated that participants were attentive and listened carefully to each other's responses. Participants were honest in their elaboration and appeared to be comfortable expressing their stories. The researcher also noted positive strong verbal and non-verbal cues. Examples of these cues included participants' firm statements, sad commentaries, and crying. The group proved to be supportive and therapeutic for all participants and no evidence of additional need for intervention or referral was noted. 


\section{Trustworthiness of the data}

According to Guba and Lincoln (1981), trustworthiness in qualitative studies is established via credibility, fittingness, consistency, and confirmability. Credibility speaks to the internal validity of the study, fittingness highlights the external validity of the study, consistency refers to the reliability of the study, and confirmability ensures the objectivity of the researcher.

Credibility. "Credibility is enhanced when researchers describe and interpret their experience as researchers" (Koch, 2006, p. 92). Based on each participant's level of participation, openness in discussing difficult hardships in their lives, and their non-verbal and verbal support of other members, it was determined that this group interview proved to be therapeutic for all participants, including the researchers. The group process was slow to start then picked up speed, strong emotions like anger and crying were expressed, and the interview ended with sense of empowerment and support marked by laughter and lightheartedness. At the conclusion of the interview, Sarah (W) said, "You know we draw strength from each other, I've certainly drawn it from all of you on more than one occasion. I hope I have done the same for you." Paula (W) replied, "That chocolate cake you make is more than enough." There was laughter and confirmation among the group and then Abigail (L) closed by saying, "That's what you should end the session with, Hellen Reddy's song 'I Am Woman' -- hear me roar."

The power of this interview resonated so strongly with the researchers that they shared the following words with the participants, "I admire each and every one of you. You have a lot to be proud of because of all the barriers you have had to overcome to get here." While two of the authors were members of this cohort and this cohort had been together for a year and half, it was evident that the information shared in this interview was not known to many in the group, including the authors. That is to say, the non-verbal behavior of those listening indicated that they were unaware of other participants' hardships. It is believed that this experience led to more cohesion and a sense of respect among cohort members.

The authors processed the group interview with each other and were stunned by the honesty and hardships these women had experienced. Prior to this interview, neither author had an idea of these women's stories.

Credibility can also be established by conducting "member-checks" (Guba \& Lincoln, 1981). Member-checks allow participants to, "clarify, extend, or modify facts, opinions, or beliefs" (Guba \& Lincoln, 1981, p. 108) expressed in the initial interview. After the authors derived the themes expressed in the interview, they shared their data and interpretations with the participants and allowed them to clarify, extend, and corroborate the data.

Fittingness. Transferability/fittingness occurs when the audience/readers can identify with the stories of the participants. "It is up to each audience to determine what, if anything, the information means and to determine for itself the information's applicability" (Guba \& Lincoln, 1981, pp. 116-117). Researchers can ensure fittingness by providing sufficient background information that allows the reader to identify with and/or make similar judgments about the data (Koch, 2006).

Consistency. Elaboration of the authors' decisions for "theoretical, methodological and analytical choices" (Koch, 2006, p. 92) can strengthen the reliability of the study. The authors of this study have made a concerted effort to provide ample information to ensure the reader that the characteristics of trustworthiness have been met.

Confirmability. The objectiveness of the data was confirmed by conducting a "member-check." Participants corroborated the findings, thus helping to establish confirmability. Another strategy to ensure confirmability was the researchers' decision regarding how to analyze the data before they analyzed it independently of each other. Lastly, the cross-referencing of themes after individually analyzing them also helped establish objectiveness. 


\section{Data Analysis}

In an effort to attain a sense of internal validity, the focus group transcript was analyzed independently by each of the four researchers after which a series of themes were discussed and collectively identified. The researchers identified common themes of resiliency by first using opencoding (Strauss \& Corbin, 1998), which allowed the researchers to identify sentences that had specific meaning. Second, the researchers used the constant comparative method (Corbin \& Strauss, 2008) to compare and contrast emergent themes from one participant with themes from subsequent participants. Finally, a more focused coding was done to verify the veracity of the noted themes (Esterberg, 2002).

In qualitative methods, theories and concepts guide the preliminary analysis of data, and, upon more in-depth analysis, new concepts emerge from the data. The researcher must then reflect back on what the emerging themes mean and how they enhance the initial theories and concepts (Esterberg, 2002). The reflexive theoretical emphasis, inherent in phenomenological qualitative research, allows for the materialization of themes and concepts throughout the research and analytical process. The emergent themes for this study included independence, perseverance, and the utilization of negative experiences as a motivational factor.

Because the sample was purposive and convenient, the analysis herein cannot be generalized to the larger population of female doctoral students nor can it be considered exhaustive in the expanse of female doctoral students in educational counseling programs. The findings that follow can, however, help to better comprehend the distinct issues that are faced by some female doctoral students and gain a more nuanced understanding of how meaning is formulated in the lives of these particular women.

\section{Results}

The research questions leading this study were the following:

(1) How do women in a Ph.D. counseling program understand and perceive their reason for academic success?, and

(2) Are there unique resiliency characteristics in women who pursue a doctoral degree?

Two overarching themes were revealed and are consistent with previous research by Amini et al. (2008): (a) attributes, attitudes, and motivation and (b) extrinsic supportive factors. However, another theme in this study, not recognized in previous literature, was the impact of (c) negative external factors. Thus, the data reveals that these women attribute their doctoral academic success to their individual attributes, such as independence, internal locus of control, resolve, and perseverance. Additionally, the utilization of a negative external factor as a source of motivation to improve themselves seems to be unique to these women. That is to say, this characteristic appears to be aligned with the SOC construct.

Findings are presented within the following subthemes that emerged from data analysis under three main headings: (a) (attribute) independence; (attitudes) internal locus of control and resolve/perseverance; (motivation) desire to demonstrate aptitude, utilizing negative experiences as motivation, education as a means of validation, and desire for more; (b) positive mentors and significant marital relationships; and (c) lack of parental/family support, lack of a good father figure, and isolation from family. Specific statements and stories are utilized to support this thematic presentation. It is important to note that ethnicities among the women, (W) for White and (L) for Latina, will be identified in order to highlight similarities and/or differences in participants. 


\section{Attributes, Attitudes, and Motivation}

\section{Independence (attribute)}

Whether it was lack of parental and/or family support, divorce of parents, abuse of the mother, and/or lack of support from educators, these women developed a strong sense of independence. It appeared that their childhood experiences taught them to become self-sufficient. That is, they learned that if they wanted to succeed they could not rely on others to help them - they would have to do it on their own. They also did not want to repeat the same mistakes their parents had made. Therefore, these women strongly believe that they are responsible for breaking the family cycle and creating a new future for themselves. It seems that the most powerful example, which created this strong sense of independence, stemmed from emotionally or physically absent fathers.

Five of the seven participants indicated this sense of independence. For example, Corina (W) did not want to leave herself in a vulnerable position where she would have to depend on a man. During the interview Jennifer (L) paraphrased Corina (W) by saying, "you are absolutely right, you walked out so that you could stand on your own two feet and support your children." Corina (W) nodded in agreement with Jennifer's (L) statement confirming this sense of independence. Paula (W) also stated, "Our father taught us that you cannot depend on a man. You'd better get yourself together so that you don't ever have to depend on them [men]." Abigail (L) agreed by saying, "My dad was a very poor provider and my mom was the one that was always struggling and we couldn't depend on him because he couldn't hold a job."

\section{Internal locus of control (attitude)}

None of the participants used stories and statements that represent an external locus of control. Instead, all seven participants believed they were in control of their academic future. For example, Jennifer (L) could have easily claimed self-defeat due to life circumstances, but she maintained an optimistic outlook and believed she was in control of her academic future. "You need to make yourself responsible to attain that opportunity," she said. Abigail's (L) comments illustrate the belief that success is inherently tied to effort: "I mentored myself because I received no encouragement [from adults]." Andrea (L) also discussed the importance of being in control of her academic future by staying focused on her ultimate goal of obtaining a doctoral degree. She provided the following perspective, “....even back in middle school, I was self-taught, 'I'm gonna finish. I'm going to earn my bachelors. I'm going to earn my masters. I'm going to earn my doctorate..."

\section{Resolve/perseverance (attitude)}

Six of the seven participants described a sense of determination in overcoming life's obstacles or challenges. Although many participants described negative life events, they also mentioned that it was important to persevere in the face of adversity. Abigail (L) recalled an experience in which she almost gave up. She described her resolve by saying,

I just will not stay put. If I fall, I'm gonna get up. It's not gonna get me. I'm gonna make it, no matter what. I have an agenda too and I'm gonna meet that agenda no matter what. . . and I thought, "Hell no [to her family's situation]." I'm not gonna stay here and see my life go past me.

When responding to Abigail's experience, Paula (W) provided a similar perspective with the following, "The same thing that happened to me, as Abigail; a real fire and resiliency to say, "you know, get out of my way or I'll run you over.'" Similarly, Laura (W), who grew up in adverse conditions and witnessed her parents' struggles, made a decision to strive for a different life that 
did not involve financial hardships. In regards to growing up in poverty, she said, "I'm doing this to prove you wrong, but I'm also doing it because, I'm gonna create a better life for myself." Jennifer (L) shared that her extended family did not support her educational endeavors and she stated, "This is what I'm getting [her degree] and you can't take it away from me and I'm gonna keep going."

\section{Desire to demonstrate aptitude (motivation)}

Six of the seven participants reported that they were motivated by the desire to demonstrate that they could succeed at the doctoral level. For example, Paula (W) grew up in poverty and faced numerous obstacles; she reported being motivated by showing former educators and her family that she could reach her Ph.D. goal, despite the circumstances. Paula stated, "I really felt like I had something to prove as far as my intelligence. Not just physical, I'm more than that." Additionally, Abigail (L) described a situation in which she was exposed to low expectations and discouraged from pursuing higher education, while her brother was given high expectations and support to reach those expectations. Abigail described the experience as follows, "I was criticized and he [brother] was encouraged to succeed, and yet he didn't go on to perform. I did."

\section{Utilizing negative experiences as motivation (motivation)}

Despite many participants experiencing conditions such as poverty, exposure to abuse, and/or lack of parental/family support, four of the seven participants reported that they utilized negative experiences as a means of motivation. For example, Abigail (L) reported that her mother was involved in a negative and violent interpersonal relationship, thereby influencing her desire to strive for a different life. Abigail commented,

When I was growing up, I didn't realize it at the time, but my mom turned out to be a motivator for me in a negative way because she was in an unhappy relationship. My father was an alcoholic and we couldn't depend on him because he couldn't hold a job. Her [my mother's] bitterness motivated me to want more and to not find myself in her situation.

Paula (W) also provided her perspective regarding the importance of negative experiences, like her parents' divorce, to illustrate the significance of higher education. She provided the following story about her parents,

He left her because he fell in love with another woman. That was one of the things that showed us that men do nothing but get you off track. You'd better get yourself together so that you don't ever have to depend on them.

Corina (W) related to Paula's story and stated, "See that was the message I got too. My father was very abusive. . . and I learned ... that I would never be in a position to ever have to depend on anybody else."

Jennifer (L), with regard to her negative childhood experience, said, "I think I've had a lot of anger, a lot of hatred ... [but] I have to say that I learned from the negative experiences." Sarah (W) provided insight into the factors that motivated her to pursue higher education with the following, "You just better get out of my way because I'm gonna knock you down on my way up, and that's exactly what my motivation was." These participants highlight the anger expressed by most and how they used this negative experience and/or feeling to fuel their motivation.

\section{Education as a means of validation (motivation)}

The distinction between 'the desire to demonstrate aptitude' and 'education as a means of validation' can be clarified by the following respective statements: "I'm going to show you that I am smart and capable" and "I'm valuable or worthy as a person because I get good grades". 
Six of the seven participants presented stories and statements which indicated that education was their vehicle to prove they were worthy and capable. Given the unstable home environments for many of this study's participants, they reported that they used education as a way to escape. They used education as a way to find a new identity in which they could label themselves as successful or resilient. For example, Abigail's (L) father was an alcoholic and did not provide high expectations, so she used education as a way to find her self-worth as a person. She shared,

I withdrew and used education to find some sort of solace; you know, a place to be able to go, to excel, at least at something. At a very early age, that's how I began to prove my worth as a person. I used education also as a way to prove to people that I was a worthy individual.

Corina (L) stated, "Grades became my way to overcome insecurity. I became motivated to make something of myself." Jennifer (L) described how education became her identity with the following comment, "I was definitely the one that was going to be the high achiever and that became my status; that became my identity."

\section{Desire for more (motivation)}

Four of the seven participants' resolve and perseverance stemmed from the desire to want a better life than their parents had. Andrea shared that her parents did not complete high school. Even though her mother later returned to earn her G.E.D., she indicated that this motivated her to achieve the highest academic level. These women are not satisfied with the status quo, as evidenced by Abigail (L) who shared, "I had a good job, I went to work at the base. But, I had such a desire for more." As stated above, Laura (W) was quoted saying, "I'm gonna create a better life for myself."

\section{Extrinsic Supportive Factors}

\section{Positive mentors}

Most of the participants recalled experiences in which they were viewed as a "teacher's pet" throughout their pre-college schooling. Although two participants reported that they had average academic achievement (pre-college), the remaining five participants described their academic achievement as high. Nonetheless, six of the seven participants acknowledged the importance of teacher/faculty mentorship, especially in their doctoral experience. Paula (W) reported that she had many college professors who served as mentors, "They wanted to see me fly." Laura (W) and Sarah (W) also agreed on the significant influence college professors had on their academic success. That is, mentorship from professors was vital to their doctoral success. Abigail (L) stated, "I tried to set up mentorships with professors who I thought would help me succeed."

\section{Significant marital relationships}

Despite some participants' negative experience with their fathers, four of the seven participants testified to the support of their spouses in their post high-school educational endeavors. In fact, most participants cited their husbands as the main reason for their academic success. It seems that the absence of their fathers (physical or emotional) did not deter these women from forming meaningful and nurturing relationships with men in their adult lives. For example, Abigail (L), who did not receive support from her father, reported that her husband helped fill the void of an absent father by providing words of encouragement and unconditional support. Abigail shared,

My spouse has always been extremely supportive. He motivates me by saying, "I share with everybody how smart you are, I share with everybody that my wife is going to be a 
doctor." And that is really ego boosting for me. I've been very blessed in that my best all around support system, for me, has been my husband.

Andrea (L) commented that her husband also provided words of encouragement. She shared,

...my husband is my support system. He believes in me, he is so proud of me and I've told you all before, he'll do anything and everything to see me accomplish this goal. He's never had a desire to go to school. He just wants to see me finish what I want to do.

Corina (W) and Jennifer (L) also shared that their husbands are their positive support system and they can count on them for anything.

\section{Negative External Factors}

Previous research on academic success has always highlighted the importance of family and/or positive extrinsic support systems as protective factors (Cavazos, Johnson, \& Sparrow, 2010; Ceballo, 2004; McMillan \& Reed, 1994; Zalaquett, 2006). A key finding of this study, not previously mentioned in resiliency research, is the use of negative external factors as a source of motivation. However, this finding can be better explained by Antonovsky's (1987) SOC construct, specifically, the comprehensibility component. Comprehensibility refers to an individual's ability to make sense of their adversity (Almedom, 2005). Given these women's level of academic success and research on protective factors, this finding (lack of parental support, lack of a good father figure, isolation from family) is in stark contrast to research on academic success. Similar to our previous discussion of the use of negative experience as motivation, the current discussion more thoroughly explains the use of "Negative External Factors" within the context of Antonovsky's sense of coherence and in direct relation to the literature on resiliency.

While several women highlighted positive factors that contributed to their success, there was an overwhelming voice of negative factors associated with family. Instead of these negative factors serving as an obstacle and deterrent to their academic achievement, these women demonstrate how they converted these negative factors into positive factors that fueled their motivation to succeed. Although some participants cited parental support as a contributing factor to their academic achievement, other participants noted a lack of parental and/or family support.

\section{Lack of parental and family support}

Five of the seven participants indicated their parents did not support their educational endeavors. Paula (W) recalled an experience in which she was given conflicting signals regarding higher education. She described the experience as follows,

But, I remember telling her [mother] in the kitchen one day, my plan and she said, "why are you even starting school, you know that you are just gonna get married and then you are gonna have to drop out." She was very serious and I didn't understand where she was coming from.

Abigail (L) also reported that her family did not support her pursuit of higher education. She provided the following perspective about being in a Hispanic family and wanting to obtain a college degree,

In fact, uh, I was criticized for being as smart as I was. I don't receive any kind of acknowledgement. When I graduated with my undergraduate degree, nobody came, and when I graduated with my graduate degree, nobody came and to this day, when I'm around, nobody will ask me, "How are you doing in school?" It's just not discussed.

Sarah (W) offered a different perspective as her family provided high expectations for males but not females. Her comment proceeded as follows, "What I always felt in the family was that there 
was no encouragement for the females." And finally, Laura (W) offered a succinct account about the high price of education: "But, I don't have much of a family, and what I have, I'm estranged from because I've chosen in my life to become educated."

\section{Lack of a good father figure}

Four of the seven participants reported that they did not have a good father figure while growing up. Although this could have negatively affected each participant, they mentioned that they learned from this situation. For example, Paula (W) provided the following perspective about her father who had extramarital relationships: "Our father taught us that you cannot depend on a man. .. The reason I feel that way is because our father had a problem with womanizing, and he left my mother when we graduated [high school]." Corina (W) reported that she could identify with Paula's experience. Corina shared,

See that was the message I got too. My father was very abusive. It makes me cry. The first 18 years of my life were total hell and all I learned from my father was that I would never be in a position to ever have to depend on anybody else.

Abigail (L) further supported this theme by saying, "My dad was a very poor provider and my mom was the one that was always struggling. . . My father was an alcoholic and we couldn't depend on him because he couldn't hold a job."

\section{Isolation from family}

Four of the seven participants also reported being isolated from family as a result of pursuing higher education. Jennifer (L) described how her family perceived her as arrogant since she made attempts to improve her life. She shared the following experience, "I've done everything to be exactly opposite [of family] and so I might have came across to some people as arrogant. I'm the only cousin that is aloof from everybody else and they don't have a relationship with me." As quoted earlier, Laura (W) also described the strained relationship with her family,

I don't have much of a family and what family I do have, I'm estranged from because I've chosen in my life to be educated. I've been criticized for it, and it sets me apart from them. I've chosen to be different, and I've been made fun of for it.

Abigail (L) described how her family reprobated her educational aspirations with the following, "I think they criticized me because I stood apart." Abigail also reflected on the segregation of her family:

...the way I dealt with this is that I separated. But that's how I dealt with it, I just detached from the whole family. Because the only way I could function through all of the chaos and the conflict was to detach and observe everybody. I became an observer; no feelings, no anything.

As has been shown, the results of this study support previous research in resiliency as well as bring to light other concepts and ideas from different theoretical fields. Table 1 lists the three major themes (Attitudes, Attributes, and Motivation, Extrinsic Supportive Factors, and Negative External Factors) and the various sub-themes for each. Included in this table is a break-down of the number of participants who were able to speak to each sub-theme. 


\section{Table 1. Emergent Themes based on Participants' Experiences and Total Percentage cited by Participants}

Attributes

Independence

$71.43 \%$

Attitudes

Internal locus of control

$100 \%$

Resolve/perseverance

$85.71 \%$

Motivation

Desire to demonstrate aptitude

$85.71 \%$

Negative experience

$57.14 \%$

Education as a means of validation

$85.71 \%$

Desire for more

$57.14 \%$

Extrinsic Supportive Factors

Positive mentors

$85.71 \%$

Significant relationships

$57.14 \%$

Negative External Factors

Lack of parental/family support

$71.43 \%$

Lack of good father figure

$57.14 \%$

Isolation from family

$57.14 \%$

\section{Discussion}

This study adds to the literature by highlighting what women perceived to be important characteristics and experiences on their road to doctoral success. Clearly, these women fit the definition of academic success, as they were able to reach the highest level of formal education, despite their lack of family support, an emotionally/physically absent father, poverty, and/or academic difficulty in high school. The qualitative data revealed personal characteristics and significant themes of academically resilient women consistent with previous resiliency research. For example, importance of mentors, internal locus of control, intrinsic motivation, and self-efficacy were themes in this study consistent with previous research. However, distinct to previous literature on resiliency, the positive effect that negative external factors had on the development of resiliency in these women was identified. This finding appears to be related to the SOC construct. In other words, these women were able to make sense of their adversity, believed they could handle whatever comes their way, and found meaning in pursuing a doctoral degree - a description of SOC's three components (Almedom, 2008).

In the case of many women in the current study, hardships, such as physical or emotional absence of the father, lack of family support, and poverty, served as important motivators - a construct not fully addressed in either the resiliency or salutogenesis theoretical models. Bernard (1997) and Thomsen (2002) do note that resilient people have the ability to disassociate one's self from unhealthy situations or people. Could these women's use of negative factors be an extension of this 
internal characteristic? Could the use of negative factors as positive motivation allude to high comprehensibility, a construct of SOC? In other words, is this characteristic (converting negative factors into positive motivators) unique to high achieving individuals?

Second, participant's childhood experiences with their parents led them to use education as a shield to avoid repeating the family cycle. Unfortunately and fortunately, these negative family experiences created a strong independence in these women. Because their family did not provide emotional support during their youth, the women in this study learned that they could not depend on anyone but themselves. Ironically, the cost of pursuing higher education and improving one's life included (a) further isolation from their family and (b) feeling different and alone.

Despite self-described feelings of isolation and independence, participants sought and noted the importance of faculty mentors during their college years and created a strong support system via their husbands and/or doctoral peers. In keeping with the resiliency research that emphasizes the importance of mentors (Ceballo, 2004; Portillo, 2007; Thomsen, 2002), many of these women attested to the importance of mentors (professors), particularly in their doctoral journey. As such, the importance of mentor support, especially among university faculty, should not be underscored. Results from the current study indicate that most of these female doctoral students were able to succeed despite the lack of parent support. However, at the college level, these women indicate that support from mentors and/or spouses were vital in their academic success -- an important note for educators.

The literature on academic success among school aged children suggests that academic success is in part related to the level of parent support/involvement. For example, studies with successful Latina/o college students have found that students receive high expectations and unconditional love and support from their parents (Cavazos, Johnson, Fielding, et al., 2010; Ceballo, 2004; Zalaquett, 2006). While the current study focused on adults enrolled in a doctoral program, there was little evidence that parent support begot doctoral success. In addition, although this study revealed a lack of parental and/or familial support, there was a strong indication of spousal support. This spousal support could be seen as the parent/family support evident in school age children.

While emotional intelligence (EI) was not the direct focus of this study, the review of literature reveals that resiliency and EI are constructs that compliment each other and that resiliency cannot occur without the enactment of EI. As such, the women in this study alluded to the implementation of EI via the establishment of healthy supportive relationships (for many, their spouses) (Nelson et al., 2003), accepting that obstacles are part of the challenge in succeeding, and actively seeking out positive role models (Sternberg, 1996). Similarly, the stories of these women support the existence of SOC.

In sum, this study reveals that individual characteristics such as intrinsic motivation, independence, internal locus of control, resolve, perseverance, and motivating self (all similar to previous resiliency research), plus the use of negative external factors as positive motivation play an important role in the academic achievement of these women.

\section{Assumptions, Limitations, and Delimitations}

The nature of this topic was extremely personal and at times required that participants recall difficult and painful experiences, thus making it difficult for some participants to fully express themselves during the focus group. Nevertheless, it is assumed that the participants were honest and open in their responses. While it is not believed that two of the authors, who were members of this same doctoral cohort, inhibited full participation of the participants, it could have also posed a limitation. 
Barriball and While (1994) state that "the willingness of respondents to be 'good' informants has [positive] implications for the validity of the data ... [and] interviewer friendliness, approach and manner towards respondents can help enormously with securing validity and reliability of the data" (p. 332). Again, while it must be recognized that two of the authors' membership in the participants' cohort could have been a limitation, it is believed that it was beneficial in soliciting each participant's honest and open disclosure. Even so, in-depth individual interviews may have provided the opportunity for more elaboration and self-disclosure.

It should also be noted that the authors of this study did not participate in the group interview as they only facilitated the process. The authors' attempts to further eliminate bias included writing notes during the interview, audio-recording the interview, and then analyzing the transcribed data independently.

There is no exact rule for the appropriate number of participants in a qualitative study as sample size is largely determined by the purpose of the inquiry (M. Q. Patton, 2002). Since the authors had sufficient data and the majority of the participants identified with the reported themes, further inquiries were not conducted. However, more interviews, especially with more diverse groups of women may prove to be beneficial to these populations - a recommendation for future research.

Additionally, although the topic of mentors was discussed by several of the women, there was not enough follow-up to truly capture the underlying issues regarding mentorship. Further study into the types of mentorship that is needed, the distinction between mentors in K-12 education, higher education, and post-graduate education, and the like, could prove useful in understanding how women and students of color succeed academically.

A couple of delimitations of this study are that the researchers chose to focus on women doctoral students in a counselor education Ph.D. program. It was decided that women in a doctoral counseling program may obtain a greater level of intrapersonal intelligence, which would provide greater self-awareness and insight about the constructs that helped them succeed. Nonetheless, the researchers recognize that female doctoral students in different programs may view or perceive their doctoral experience differently.

Another delimitation of this study was that the researchers chose to conduct this interview as a group instead of individually. This could have influenced the direction of the discussion and led some women to discuss other topics than if they were interviewed individually. However, the group discussion could have also brought up topics participants would not have considered or discussed individually.

While these findings may not be generalizable, it lays the groundwork upon which future research studies can be implemented that look into and expand upon the important findings in this study. Myers (2000) contends that "small qualitative studies can gain a more personal understanding of the phenomenon and the results can potentially contribute valuable knowledge to the community" (n.p.). As such, it is believed that the findings of this study, in particular, participants' tendency to use negative experiences as motivation to succeed, will contribute to the existing research on resiliency and salutogenesis theories.

\section{Implications for Practice}

Research on at-risk students has implied that outnumbering risk factors, like poverty or negative home environment, with protective factors, like positive role models/mentors, is the key to academic success (Rak \& Patterson, 1996). However, results from the current study indicate that these women used these risk factors as sources of motivation to achieve. While protective factors, like positive mentors, were present in these participants, it seems that these participants' internal locus of control, resolve, perseverance, and independence, and their ability to transform some- 
thing negative into something positive played a more important role in the academic achievement of these women. This conclusion is based on the fact that four of the participants mentioned that mentors did not play a significant role in their education until their undergraduate and graduate studies. That is to say, for these women the mentors at the undergraduate and graduate level had a significant impact on their academic success.

The results from the current study indicate that helping individuals channel negative experiences into motivation to succeed is a viable and worthy endeavor. It is important for educators to avoid the belief that their efforts are futile when working with at-risk students whose parents are not supportive of academic success. Teachers must do what is within their power to influence and change at-risk students toward a positive academic trajectory.

By the same token, the authors of the current study understand that all students are different and some students do not use the same motivational strategies to overcome obstacles or barriers. Martinez (2003) stated,

Many Latino students are still singled out early in the educational process as not having the aspiration and/or ability to conquer the rigors of a college experience. As a result, a significant number of children resign themselves to mediocrity and internalize a sense of failure before an attempt is made to be successful. (p. 15)

The aforementioned example is in contrast with results from the current study in which doctoral students used negative experiences as motivation to persevere. In light of previous research and this study's findings, educators must be aware that students interpret and utilize different coping responses when faced with low expectations from educators and/or parents.

This study's findings also have implications for doctoral programs. Support groups, in the form of doctoral cohorts, may provide doctoral students with an opportunity to identify their struggles as well as their coping responses to overcome challenges. Similar to participants in the current study, a focus group or support group may allow doctoral students to share their common experiences with other classmates, thereby providing increased support and encouragement to persist in the face of adversity.

Additionally, counselor educators can create assignments that allow students to reflect on their experiences and motivation to persevere. Previous research has highlighted the importance of self-reflection in helping students navigate their doctoral studies (Castellanos, Gloria, \& Kamimura, 2006; Kamimura, 2006). For example, in a personal account of a doctoral student's experience, Kamimura (2006) commented that he made meaning out of his experiences by engaging in a number of stages, including self-awareness and self-reflection. Therefore, doctoral students would benefit from counselor educators creating an environment that engages in self-reflection with regard to their doctoral study experiences and perspectives. Lastly, counselor educators must pay special attention to the role of mentoring in the resiliency among female doctoral students. As illustrated in the current study, some doctoral students contend that although they did not receive parental support and encouragement, mentoring from faculty helped them navigate their doctoral studies.

\section{Conclusions and Further Research}

Future research must explore the following question: When faced with low expectations of others or negative life events, why do some students give up (Martinez, 2003), while others treat low expectations as something to overcome (Antonovsky, 1987)? Participants in this study highlight using negative experiences and/or low expectations as motivation to succeed. Perhaps there is something intrinsic to these women's personality whereby negative obstacles are used as a way to ignite motivation to succeed. Therefore, future research should include the exploration of sense of 
coherence in academically successful people, as the impact of negative obstacles increased the resiliency of these women. It is interesting to consider whether or not the participants of this study would have made the same life choices and displayed the same degree of resiliency without life's hardships. Maybe Antonovsky's (1987) SOC scale can reveal the personality types that foster the development of academic resiliency in female doctoral students.

While SOC is a relatively popular research construct in other fields, its relation to academic success/resiliency has remained largely unexamined. Further, the implication that SOC was evident in these women, exemplifies the need for cross-disciplinary studies. It is in researchers' best interest to determine if there are any differences in SOC between those who are academically successful and those who are not. Future studies on SOC in academically successful women may reveal unique resiliency characteristics, otherwise unknown.

Similarly, some participants from the current study reported that they had siblings who were exposed to the same home and school environments but were not motivated to achieve academic success. Is it possible that the personality traits (independence, internal locus of control, resolve, and perseverance) of these women are absent or of lesser degree in their siblings? Future research that examines the intrinsic factors/personality traits that differentiate academically successful doctoral students from their siblings who are not academically successful is also warranted. For example, administering the Antonovsky's (1987) SOC scale to high achieving individuals and their siblings would provide some answers to the aforementioned research questions.

Another research area worthy of investigation is the manner in which individuals cognitively utilize negative experiences as a source of motivation to succeed. That is to say, if the tendency to use negative experiences as motivation to succeed is not an intrinsic personality factor, then we must discover the psychological process that individuals use to convert these negative experiences into positive motivation. This line of research may lead to an emphasis on specific counseling theories that would help clients and students avoid becoming victims of their circumstances.

Notwithstanding limitations, this study generated useful information which stimulated further reflection on the role of educators. This study suggests that pre-college and college educators can positively impact the academic success of students despite their impoverished backgrounds and/or unsupportive parents. Since some participants grew up knowing they could not depend on their parents or teachers, they had an overwhelming need to be self-dependent and self-reliant. Hence, all educators, especially doctoral level educators, should not underestimate the power of their encouragement and mentorship, as it could be vital in success of female doctoral students.

\section{Acknowledgements}

Special thanks and acknowledgement to the women who participated in this study. All of these women have contributed greatly to their fields and continue to inspire other women to succeed.

\section{References}

Almedom, A. M. (2005). Resilience, hardiness, sense of coherence, and posttraumatic growth: All paths leading to "Light at the end of the tunnel"? Journal of Loss and Trauma, 10, 253-265. doi: $10.1080 / 15325020590928216$

American College Personnel Association (ACPA) College Student Educators International, ACPA Executive Committee. (2006). Statement of ethical principles and standards. Retrieved from http://www2.myacpa.org/ethics/statement.php 
Amini, M., Dehghani, M. R., Kojuri, J., Mahbudi, A., Bazrafkan, L., Saber, M,... Ardekain, G. S. (2008). A qualitative study of factors associated with medical students' academic success. Journal of Social Sciences, 4, 347-351. doi:10.3844/jssp.2008.347.351

Antonovsky, A. (1979). Health, stress and coping. San Francisco, CA: Jossey-Bass.

Antonovsky, A. (1987). Unraveling the mystery of health: How people manage stress and stay well. San Francisco, CA: Jossey-Bass.

Bandura, A. (1995). Self- efficacy in changing societies. New York, NY: Cambridge University Press.

Barribal, K. L., \& While, A. (1994). Collecting data using a semi-structured interview: A discussion paper. Journal of Advanced Nursing, 19, 328-335. Retrieved from http://www.journalofadvancednursing.com/

Bernard, B. (1997). Turning it around for all youth: From risk to resilience (Report No. EDO-UD-97-7). New York, NY: Office of Educational Research and Improvement. (ERIC Document Reproduction Service No. ED412309)

Bosworth, K., \& Earthman, E. (2002). From theory to practice: School leaders' perspectives on resiliency. Journal of Clinical Psychology, 58, 299-306. doi:10.1002/jclp.10021

Brehm, S. S., Kassin, S., \& Fein, S. (2005). Social psychology. Boston, MA: Houghton Mifflin Company.

Casanova, P. F., Garcia-Linares, M. C., de la Torre, M. J., \& de la Villa Carpio, M. (2005). Influence of family and socio-demographic variables on students with low academic achievement. Educational Psychology, 25, 423-435. doi:10.1080/01443410500041888

Castellanos, J., \& Gloria, A. M. (2007). Research considerations and theoretical application for best practices in higher education: Latina/os achieving success. Journal of Hispanic Higher Education, 6, 378396. doi: $10.1177 / 1538192707305347$

Castellanos, J., Gloria, A. M., \& Kamimura, M. (2006). Enderezendo el camino/Straightening the path: Dispelling myths and providing directions for Latina/o doctoral students. In J. Castellanos, A. M. Gloria, \& M. Kamimura (Eds.), The Latina/o pathway to the Ph.D. (pp. 191-200). Sterling, VA: Stylus.

Cavazos, A. G., \& Cavazos, J. (2010). Understanding the experiences of Latina/o students: A qualitative study for change. American Secondary Education, 9, 1-17. Retrieved from http://www.ashland.edu/ase

Cavazos, J., Johnson, M. B., Fielding, C. F., Cavazos, A. G., Castro, V., \& Vela, L. (2010). A qualitative study of resilient Latina/o college students. Journal of Latinos and Education, 9, 172-188. doi: $10.1080 / 15348431003761166$

Cavazos, J., Johnson, M. B., \& Sparrow, G. S. (2010). Overcoming personal and academic challenges: Perspectives from Latina/o college students. Journal of Hispanic Higher Education, 9, 304-316. doi: $10.1177 / 1538192710380744$

Ceballo, R. (2004). From the barrios to Yale: The role of parenting strategies in Latino families. Hispanic Journal of Behavioral Sciences, 26, 171-186. doi:10.1177/0739986304264572

Corbin, J., \& Strauss, A. (2008). Basics of qualitative research (3rd ed.). Thousand Oaks, CA: Sage Publications, Inc.

Council of Graduate Schools (2008). Ph.D. completion and attrition: Analysis of baseline demographic data from the Ph.D. completion project -- executive summary. Retrieved March 18, 2011, from http://www.phdcompletion.org/information/Executive_Summary_Demographics_Book_II.pdf

Curtis, J. W. (2005). Editor's notes. New Directions for Higher Education, 130, 1-4.

Eitel, S. J., \& Martin, J. (2009). First-generation female college students' financial literacy: Real and perceived barriers to degree completion. College Student Journal, 43, 616-630. Retrieved from http://www.projectinnovation.biz/csj_2006.html

Esterberg, K. G. (2002). Qualitative methods in social research. Boston, MA: McGraw Hill. 
Evans-Winters, V. E. (2003). Reconstructing resilience: Including African-American female students in educational resiliency research. Dissertation Abstracts International, 64(03), 854. (UMI No. 3086056)

Gardner, S. K. (2008). Fitting the mold of graduate school: A qualitative study of socialization in doctoral education. Innovative Higher Education, 33, 125-138. doi:10.1007/s10755-008-9068-x

Gonzalez, C. M. (2002). The Latina/o faculty: A perilous journey to the ivory tower in higher education. Dissertation Abstracts International, 63(02), 768. (UMI No. 3042570)

Grayson, R. C. (2001). Summer camp as an intervention for at-risk youth. (Doctoral dissertation, Claremont Graduate University, 2001). Dissertation Abstracts International. (UMI No. 3015952)

Guba, E. G., \& Lincoln, Y. S. (1981). Effective evaluation: Improving the usefulness of evaluation results through responsive and naturalistic approaches. San Francisco, CA: Jossey-Bass Publishers.

Harrop, E., Addis, S., Elliott, E., \& Williams, G. (2006). Resilience, coping and salutogenic approaches to maintaining and generating health: A review. Cardiff University: Cardiff Institute of Society, Health and Ethics. Retrieved from http://www.cardiff.ac.uk/socsi/cishe/pages/Publications/Behaviour_ChangeReview_on_Resilence coping and_salutogenic approaches to health.pdf

Hassinger, M., \& Plourde, L. A. (2005). "Beating the odds": How bi-lingual Hispanic youth work through adversity to become high achieving students. Education, 126, 316-327.

Heenan, D. (2002). Women, access and progression: An examination of women's reasons for not continuing in higher education following the completion of the certificate in women's studies. Studies in Continuing Education, 24, 39-55. doi:10.1080/01580370220130431

Hoskins, C. M., \& Goldberg, A. D. (2005). Doctoral student persistence in counselor education programs: Student-program match. Counselor Education and Supervision, 44, 175-188. Retrieved from http://www.unco.edu/ces/

Hutchinson, S., \& Skodol-Wilson, H. (1992) Validity threats in scheduled semistructured research interviews. Nursing Research, 41(2), 117-119. doi: 10.1097/00006199-199203000-00012

Kamimura, M. (2006). Finding my way: Enculturation to the Ph.D. In J. Castellanos, A. M. Gloria, \& M. Kamimura (Eds.), The Latina/o pathway to the Ph.D. (pp. 191-200). Sterling, VA: Stylus.

Koch, T. (2006). Establishing rigour in qualitative research: The decision trail. Journal of Advanced Nursing, 53(1), 91-103.

Lewis, C. W., Ginsberg, R., Davies, T., \& Smith, K. (2004). The experiences of African American Ph.D. students at a predominantly white Carnegie I-research institution. College Student Journal, 38, 231245.

Martinez, M. D. (2003). Missing in action: Reconstructing hope and possibility among Latino students placed at risk. Journal of Latinos and Education, 2, 13-21. doi:10.1207/S1532771XJLE0201_3

McMillan, J. H., \& Reed, D. F. (1994). At-risk students and resiliency: Factors contributing to academic success. Clearing House, 67, 137-140.

McNair, R., \& Johnson, H. D. (2009). Perceived school and home characteristics as predictors of school importance and academic performance in a diverse adolescent sample. North American Journal of Psychology, 11, 63-84. Retrieved from http://najp.8m.com/

Montano, R. R. (1998). Resiliency characteristics of women leaders in education. Dissertation Abstracts International, 60(02), 300. (UMI No. 9918746)

Montell, F. (1999). Focus group interviews: A new feminist method. NWSA Journal, 11, 44-71. doi: 10.2979/NWS.1999.11.1.44

Morales, E. E. (2008). Academic resilience in retrospect: Following up a decade later. Journal of Hispanic Higher Education, 7, 228-248. doi:10.1177/1538192708317119 
Myers, M. (2000, March). Qualitative research and the generalizability question: Standing firm with Proteus. [30 paragraphs]. The Qualitative Report [On-line serial], 4(3/4). Available: http://www.nova.edu/ssss/QR/QR4-1/myers.html

Nay-Brock, R. M. (1984). A comparison of the questionnaire and interviewing techniques in the collection of sociological data. Australian Journal of Advanced Nursing, 2(1), 14-23. Retrieved from http://www.ajan.com.au/

Nelson, D. B., \& Low, G. R. (2003). Emotional intelligence: Achieving academic and career excellence. Upper Saddle River, NJ: Prentice Hall.

Nelson, D. B., Low, G. R., Stottlemyer, B. G., \& Martinez, S. (2003). PRM personal responsibility map: Professional manual. Oakwood Solutions.

Olivares, O. J., Peterson, G., \& Hess, K. P. (2006). An existential-phenomenological framework for understanding leadership development experiences. Leadership \& Organization Development Journal, 28(1), 76-91. doi: 10.1108/01437730710718254

Patton, L. D., \& Harper, S. R. (2003). Mentoring relationships among African American women in graduate and professional school. New Direction for Student Services, 104, 67-77. doi:10.1002/ss.108

Patton, M. Q. (2002). Qualitative research and evaluation methods (3rd ed.). Thousand Oaks, CA: Sage Publications.

Portillo, S. (2007). Mentoring minority and female students: Recommendations for improving mentoring in public administration and public affairs programs. Journal of Public Affairs Education, 13(1), 103-113. Retrieved from http://www.naspaa.org/initiatives/jpae/jpae.asp

Protivnak, J. J., \& Foss, L. L. (2009). An exploration of themes that influence the counselor education doctoral student experience. Counselor Education and Supervision, 48, 239-256. Retrieved from http://www.unco.edu/ces/

Radke-Yarrow, M., Sherman, T., Mayfield, A., \& Stilwell, J. (1990). Hard growing: Children who survive. In J. Rolf, A. S. Masten, D. Cicchetti, K. H. Nuechterlein, \& S. Weintraub (Eds.), Risk and protective factors in the development of psychopathology (pp. 97-119). New York, NY: Cambridge University Press.

Rak, C. F., \& Patterson, L. E. (1996). Promoting resilience in at-risk children. Journal of Counseling \& Development, 74, 368-373. Retrieved from http://www.counseling.org/publications/journals.aspx

Rotter, J. (1954). Social learning and clinical psychology. Englewood Cliffs, NJ: Prentice-Hall.

Ruiz, Y. (2002). Predictors of academic resiliency for Latino middle school students. Dissertation Abstracts International, 63(02), 206. (UMI No. 3043416)

Salovey, P., \& Mayer, J. D. (1990). Emotional Intelligence. Imagination, Cognition and Personality, 9, 185-211. doi:10.2190/DUGG-P24E-52WK-6CDG

Smith, L. (1992). Ethical issues in interviewing. Journal of Advanced Nursing, 17(1), 98-103. doi: 10.1111/j.1365-2648.1992.tb01823.x

Sternberg, R. J. (1996). Successful intelligence: How practical and creative intelligence determine success in life. New York, NY: Simon \& Schuster.

Strauss, A., \& Corbin, J. (1998). Basics of qualitative research: Techniques and procedures for developing grounded theory (2nd ed.). Thousand Oaks, CA: Sage.

Strumpfer, D. J. W. (2005). Standing on the shoulders of giants: Notes on early positive psychology (Psychofortology). South African Journal of Psychology, 35(1), 21-45.

Thomsen, K. (2002). Building resilient students: Integrating resiliency into what you already know and do. Thousand Oaks, CA: Corwin Press. 
Torres, L., \& Driscoll, M. W. (2010). Racial microaggressions and psychological functioning among high achieving African-Americans: A mixed-methods approach. Journal of Social and Clinical Psychology, 29, 1074-1099. doi: 10.1521/jscp.2010.29.10.1074

Trevino, R. E. (2000). Parent involvement and remarkable student achievement: A study of Mexican-origin families of migrant high-achievers. Dissertation Abstracts International, 61(11), 4251. (UMI No. 9992929)

U.S. Bureau of the Census. (2009a). Educational attainment of the population 25 years and over, by selected characteristics: Female. Retrieved March 18, 2011, from http://www.census.gov/hhes/socdemo/education/data/cps/2009/tables.html

U.S. Bureau of the Census. (2009b). Educational attainment of the population 25 years and over, by selected characteristics: Male. Retrieved March 18, 2011, from http://www.census.gov/hhes/socdemo/education/data/cps/2009/tables.html

U.S. Bureau of the Census. (2009c). Educational attainment of the population 18 years and over, by age, sex, race and Hispanic origin: 2009. Retrieved March 18, 2011, from http://www.census.gov/hhes/socdemo/education/data/cps/2009/tables.html

U.S. Department of Education, National Center for Education Statistics. (2009). Digest of Education Statistics, 2008 (NCES 2009-020), Chapter 3. Table 190. Total fall enrollment in degree-granting institutions, by sex of student and attendance status: Selected years, 1970-2007. Retrieved March 18, 2011, from http://nces.ed.gov/programs/digest/d08/tables/dt08_190.asp

Weiler, K. (1989). Women's history and the history of women teachers. Journal of Education, 171, 9-30.

Werner, E. E., \& Smith, R. S. (1992). Overcoming the odds: High risk children from birth to adulthood. Ithica, NY: Cornell University Press.

Wilkinson, S. (1998). Focus groups in feminist research: Power, interaction, and the co-construction of meaning. Women's Studies International Forum, 21, 111-125. . Retrieved from http://www.elsevier.com/wps/find/journaldescription.cws_home/361/description\#description

Wolin, S., \& Wolin, J. (1993). The resilient self. New York: Villard Books.

Zalaquett, C. (2006). Study of successful Latina/o students. Journal of Hispanic Higher Education, 5, 3547. doi:10.1177/1538192705282568

Zalaquett, C., \& Feliciano, P. (2004). The Latino student success stories research: Providing role models to Latino students. SAEOPP Journal, 21, 7-22.

\section{Biographies}

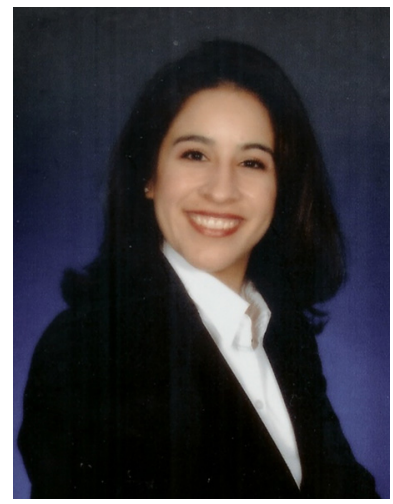

Veronica Castro, Ph.D. is an assistant professor in the Guidance and Counseling Program at the University of Texas-Pan American. Her formal education began at UT-Austin and culminated in the completion of her Ph.D. in Counselor Education from Texas A\&M University - Corpus Christi. She has eight years of experience in the public education system where she served as a high school teacher, elementary counselor and middle school counselor. Her research experience and interests encompass school counselor education, the role of the school counselor, counseling GLBT youth, emotional intelligence and resiliency in students. She has taught the following graduate level courses: counseling techniques, personal and social development, human growth and development, introduction to school counseling, and practicum. In addition to teaching graduate students, she actively serves her community as a Licensed Professional Counselor. Her extensive contact with children and adolescents, ranging but not limited to different ethnic, gender, and sexual orientation backgrounds has provided her with a rich counseling experience. She currently lives with her family in South Texas. 


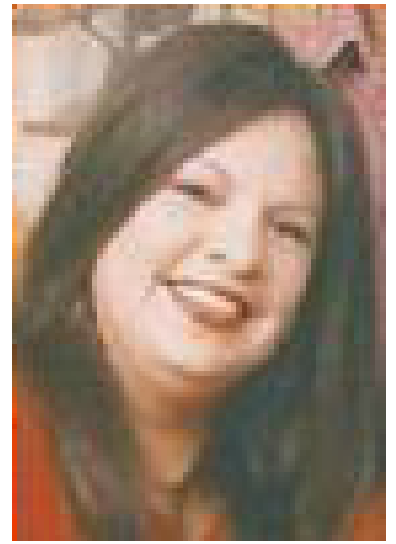

Elda E. Garcia, Ph.D., is the Director of Testing for the Corpus Christi Independent School (CCISD). Dr. Garcia holds a Bachelor of Arts in Psychology/Sociology from Texas A\&I University and a Master of Science in Psychology from Texas A\&M-Kingsville. She received her doctoral degree in Counselor Education from Texas A\&M UniversityCorpus Christi. As CCISD's Director of Testing, Dr. Garcia oversees the district's local and state assessment programs. She works with elementary, middle, high school and special campus principals and assistant principals to ensure that the requirements of the District and Texas State Assessment Program are met. Dr. Garcia is a contributing author to Substance Abuse Counseling, 3rd and 4th Editions published by Prentice-Hall and has presented at numerous state and national professional conferences. Additionally, Dr. Garcia has worked in the fields of counseling and medical social work. She is a licensed chemical dependency counselor and a licensed social worker. She has worked with special populations including: at-risk youth, criminal justice clients, and chemically dependent clients, the elderly and terminally ill children.

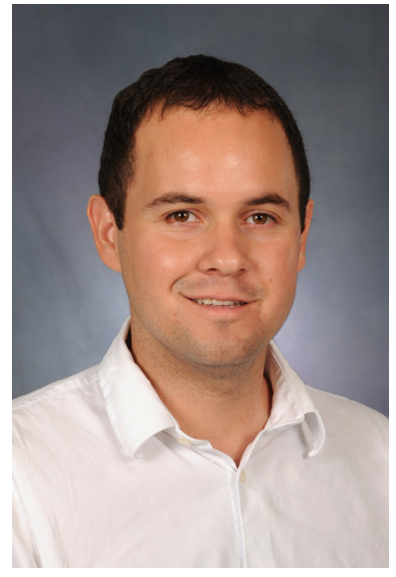

Javier Cavazos Jr. is a doctoral student in Counselor Education at Texas A\&M University-Corpus Christi. He has co-authored 14 peer reviewed publications, mostly on factors that help Latina/o students pursue and succeed in higher education. He currently works as a Seminar Leader in the First-Year Learning Communities Program at Texas A\&M University-Corpus Christi.

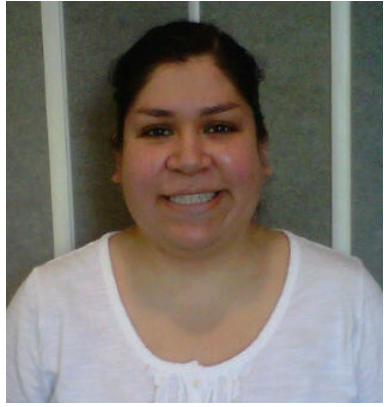

Alma Castro is a sociology $\mathrm{PhD}$ candidate at the University of Massachusetts -Amherst. She received her BA in sociology from Boston College and MA in sociology from Texas State University-San Marcos. She has worked as a qualitative researcher and was a part of a multi-site, multi-year research study with MDRC on male students of color at community colleges across the U.S. The ensuing publication, Terms of Engagement: Men of Color Discuss Their Experiences in Community College was published by MDRC in 2010. Ms. Castro is currently in her third year as a PD candidate in the sociology department at the University of Massachusetts-Amherst. Her research and teaching interests include data collection and methodology, quantitative and qualitative research methods, and critical theory. Aside from doing research and teaching in the department, she also works at the University's IRB. 